\title{
Impact of Surgeons' Experience on Oncologic Outcomes in Women Undergoing Laparoscopic Radical Hysterectomy for Cervical Cancer: A Comparison of the First 50 and last 50 Cases
}

\section{Pengfei Li}

Southern Medical University Nanfang Hospital

\section{Shan Kang}

Hebei Medical University Fourth Affiliated Hospital and Hebei Provincial Tumor Hospital Jianxin Guo

Third Military Medical University Daping Hospital and Research Institute of Surgery

\section{Shiqi Liang}

Southern Medical University Nanfang Hospital

\section{Ying Yang}

Xinqiao Hospital

\section{Shaoguang Wang}

Qindao University Medical College Affiliated Yantai Yuhuangding Hospital

\section{Xiaonong Bin}

Guangzhou Medical University

\section{Jinghe Lang}

Peking Union Medical College Hospital

\section{Ping Liu}

Southern Medical University Nanfang Hospital

Chunlin Chen ( $\square$ ccl1@smu.edu.cn )

Southern Medical University Nanfang Hospital

\section{Research article}

Keywords: cervical cancer, laparoscopy, surgical experience, learning curve, oncological outcome

Posted Date: June 8th, 2020

DOI: https://doi.org/10.21203/rs.3.rs-26906/v1

License: (c) (1) This work is licensed under a Creative Commons Attribution 4.0 International License. Read Full License 
Page $2 / 27$ 


\section{Abstract}

Objectives: To compare the oncological outcomes of the first 50 laparoscopic radical hysterectomy (LRH) surgeries with the last $50 \mathrm{LRH}$, performed by high volume surgeons, for cervical cancer patients.

Design: A nationwide multicentre retrospective cohort study

Setting: Clinical diagnosis and treatment of cervical cancer patients in mainland China (Four C) database.

Population: women with early cervical cancer undergone LRH.

Methods: We retrospectively analyzed the oncological outcomes of 1004 cervical cancer patients who underwent LRH performed by 19 surgeons. They were divided into two groups according to the sequence of operations, the first 50 and the last 50 patients with LRH. Kaplan-Meier survival analysis and log-rank test, Cox proportional risk regression model and propensity score matching were used.

Main Outcome Measures: 5-year overall survival (OS) and disease-free survival (DFS) rates.

Results: There were no significant differences in the 5-year OS and DFS between first 50 patients with LRH group ( $n=413)$ and last 50 patients with LRH group ( $n=591)$ (OS: $p=0.388 ; D F S: p=0.226)$. The last 50 cases of LRH was not an independent risk factor for OS and DFS in early cervical cancer patients $(p=0.830, p=0.300)$. After propensity score matching, similar outcomes were observed $(n=364: 364 \llbracket 0 S: P=$ $0.764 ; \mathrm{DFS}: \mathrm{P}=0.705)$.

Conclusions: The oncological outcomes of the first $50 \mathrm{LRH}$ surgeries were similar to those of the last 50 surgeries in patients with early-stage cervical cancer. Increase in the surgeons' experience did not improve significantly with oncological outcomes of patients with early stage cervical cancer after LRH.

\section{Introduction}

Radical hysterectomy in combination with pelvic lymphadenectomy is the standard treatment for nonfertility sparing stage IA1 cervical cancer with positive lymphovascular space invasion (LVSI) to stage IIA2 cervical cancer. NCCN guideline ${ }^{1}$ used to indicate that laparotomy or minimally invasive surgery (MIS) are acceptable for patients with early stage cervical cancer. Due to these suggestions, MIS was widely used. However, in November 2018, Ramirez et al. ${ }^{2}$ published a multicentre, phase III randomized controlled trial in the New England Journal of Medicine, which reported that laparoscopic radical hysterectomy (LRH) was associated with worse OS and DFS rates after 4.5 years in patients with early stage cervical cancer than was abdominal radical hysterectomy (ARH). In the same period, retrospective cohort data from Melamed et al. ${ }^{3}$ were also published, and LRH was reported to result in a shorter OS than $\mathrm{ARH}$. These two studies overturned the traditional understanding of laparoscopic surgery in gynecologic oncology. Cervical Cancer Guidelines (Version 3.2019) released by NCCN Clinical Practice 
Guidelines in Oncology in $2019^{4}$ no longer recommends laparoscopic surgery as the preferred surgical approach for the treatment of early stage cervical cancer .

Although these two studies suggested that the long-term prognosis was poor for patients that underwent LRH with early stage cervical cancer, the study did not provide reasons for the poor efficacy of laparoscopy. Among many possible causes, surgical experience was often thought to influence oncological outcomes. Therefore, we suggest a hypothesis: was the surgeons' experience one of the reasons for the poor outcomes of LRH surgery? However, the previous studies on the learning curve of LRH for early stage cervical cancer focused on operative techniques such as operation time, bleeding volume, incidence of intraoperative and postoperative complications and perioperative outcomes, rarely focused on long-term oncological outcomes and ignored the influence of surgeons' experience on the long-term oncological outcomes of patients with early stage cervical cancer. In addition, in most of the studies, single-center, single-surgeon and small samples were included.

To test this hypothesis, we explored whether the experience of surgeons affects the efficacy of LRH based on the clinical diagnosis and treatment of cervical cancer in China database. This study is a multicenter retrospective study. We compare the oncological outcomes of the first $50 \mathrm{LRH}$ surgeries and the last 50 LRH surgeries of surgeons for patients with early stage cervical cancer.

\section{Materials And Methods}

\subsection{Data Source}

The data used in this study is from the Clinical Diagnosis and Treatment for Cervical Cancer in China (Four C) Database, which covers 46313 patients with cervical cancer in 37 hospitals in mainland China from January 2004 to December 2016. The establishment of this database was approved by the Ethics Committee of the Southern Hospital of Southern Medical University. The ethical approval number is NEEC-2017-135, and the clinical research registration number is CHiCTR1800017778 (International Clinical Trials Registry Platform Search Port, http://apps.who.int/trialsearch/).

All follow-up procedures were carried out by trained gynecological oncology staff at each centre to keep the patients' personal data confidential and to provide disease management guidance at the same time. The follow-up information was gathered through the return visit system or telephone follow-up, including survival status, time of death, recurrence time, recurrence site, treatment after recurrence. The oncological outcomes were estimated according to the recorded information, and the last day of the return visit or telephone follow-up was defined as the last follow-up. We follow-up all patients, but the follow-up rate of oncological outcomes was $72.7 \%$ in this database. Detailed data collection requirements and database establishment processes were described in our previously published study. 5,6

Laparoscopic cervical cancer surgery started to be conducted in all participating institutions after 2004,so the first LRH cases performed by surgeons after this year were included in this database. In this study, 
more than 600 surgeons were enrolled. In the database, 19 surgeons who completed more than 100 cases of LRH were enrolled. The operation cases were sorted according to the operation date. The first 50 patients with LRH were considered a group and the last 50 patients with LRH were considered another group. The patients were grouped according to the date of the operation, regardless of whether they met the inclusion or exclusion criteria.

In this database, the FIGO stage was recorded and corrected by tumour size according to the FIGO 2009 staging system. Tumour size was evaluated using magnetic resonance imaging, computed tomography, ultrasound, physical examination or postoperative pathological records.

\subsection{Inclusion and exclusion criteria}

The patients' inclusion criteria were as follows: age 18 years or older; cervical cancer diagnosis of FIGO stage IA1 with positive LVSI to stage IIA2; squamous cell carcinoma, adenocarcinoma, or adenosquamous cell carcinoma; a history of laparoscopic surgery; type QM-B or QM-C ${ }^{7}$ hysterectomy with pelvic lymphadenectomy with or without paraaortic lymphadenectomy; and a postoperative survival outcome. Surgeons who performed 100 or more LRH surgeries were also included, and we excluded patients if they had neoadjuvant chemotherapy or radiotherapy before surgery. Patients with pregnancy or other types of malignant tumours were excluded, too.

In subgroup analyses, the standard postoperative adjuvant therapy was defined as cervical cancer patients with one or more high-risk factors (lymph node metastasis, parametrial involvement, and surgical margin invasion) or patients with two or more intermediate-risk factors (deep cervical stromal invasion, tumor size $>4 \mathrm{~cm}$, and LVSI were received radiotherapy or chemo-radiotherapy. ${ }^{8}$

\subsection{Outcome measures}

The overall 5-year survival rate (OS) and disease-free survival rate (DFS) were calculated. OS was defined as the time from diagnosis to death for any reason. DFS was defined as the time from diagnosis to death or recurrence for any reason. Data regarding patients with no evidence of recurrence or death were censored at the date of last follow-up.

\subsection{Statistical methods}

Metrological data were expressed as the mean (+ standard deviation) and categorized data by percentage (\%). The Kaplan-Meier curve was used to describe the changes in survival outcomes, and the log-rank test was used to compare the differences in survival curves among groups. A Cox proportional risk regression model was used to adjust for case mix, determine independent risk factors, and calculate the relevant risk and 95\% confidence interval. The statistical software used was SPSS 23.0 (SPSS Inc., Chicago, IL, USA). $\mathrm{P}<0.050$ was considered statistically significant. In the multivariate model, we also included the following known variables that may affect prognosis to reduce confounding effects: FIGO stage, age, histology, tumour size, depth of the stromal invasion, LVSI, lymph node metastasis, surgical margin invasion, parametrial tumour invasion, and postoperative adjuvant treatment. 
To control confounding factors, each patient in the first 50 patients with LRH group was matched to one patient in last 50 patients with LRH group using the known risk factors for recurrence or death using propensity score matching (PSM).

\section{Results}

A total of 46313 patients with cervical cancer were included from the large database on the clinical diagnosis and treatment of cervical cancer in China. 7670 patents received LRH, and there were 19 surgeons operating more than $100 \mathrm{LRH}$. The mean LRH of 19 surgeons is $201.2 \pm 85.2$ (range 102 to 375). According to the inclusion and exclusion criteria, 1004 patients with early stage cervical cancer were finally included. The data filtering process is shown in Fig. 1.

Median follow-up of censored cases was 35.3 months (interquartile range, 26.0-51). Clinico-pathologic characteristics of two groups before and post matching are shown in Table 1. The first 50 patients with LRH group was younger than another group. In both groups, patients with IB1 stage disease accounted for most $(66.1 \%$ vs. $65.0 \%)$. The first 50 patients with LRH group were more likely to have lower stage disease, whereas the last 50 patients with LRH group were more likely to have higher stage disease. Tumours in the first 50 patients with LRH group were less likely to have lymphovascular space invasion and deep stromal invasion (all, $\mathrm{P}<0.05$ ). 
Table 1

Clinical and pathological parameters of first 50 patients with LRH group and last 50 patients with LRH group

\begin{tabular}{|c|c|c|c|c|c|c|}
\hline & before match & & $P$ & after matche & & $P$ \\
\hline Characteristic & $\begin{array}{l}\text { First } 50 \\
\text { patients with } \\
\operatorname{LRH}(\mathrm{n}=413)\end{array}$ & $\begin{array}{l}\text { Last } 50 \\
\text { patients with } \\
\operatorname{LRH}(\mathrm{n}=591)\end{array}$ & & $\begin{array}{l}\text { First } 50 \\
\text { patients } \\
\text { with LRH(n } \\
=364)\end{array}$ & $\begin{array}{l}\text { Last } 50 \\
\text { patientes } \\
\text { with LRH(n } \\
=364)\end{array}$ & \\
\hline Age(years) & $46.3 \pm 8.913$ & $49.1 \pm 9.637$ & <. 001 & $47.1 \pm 8.789$ & $47.3 \pm 9.137$ & 0.701 \\
\hline FIGO stage & & & $\hat{0} .001$ & & & 0.191 \\
\hline IA & $13(3.1 \%)$ & $13(2.2 \%)$ & & $11(3.0 \%)$ & $10(2.7 \%)$ & \\
\hline IB1 & $273(66.1 \%)$ & $384(65.0 \%)$ & & $257(70.6 \%)$ & $268(73.6 \%)$ & \\
\hline IB2 & $35(8.5 \%)$ & $48(8.1 \%)$ & & $32(8.8 \%)$ & $30(8.2 \%)$ & \\
\hline$\| \mathrm{A} 1$ & $56(13.6 \%)$ & $111(18.8 \%)$ & & $50(13.7 \%)$ & $50(13.7 \%)$ & \\
\hline IIA2 & $7(1.7 \%)$ & $28(4.7 \%)$ & & $7(1.9 \%)$ & $0(0.0 \%)$ & \\
\hline $\mid \mathrm{B} / \mathrm{II} \mathrm{A}$ & $29(7.0 \%)$ & $7(1.2 \%)$ & & $7(1.9 \%)$ & $6(1.6 \%)$ & \\
\hline Histologic type & & & 0.307 & & & 0.732 \\
\hline $\begin{array}{l}\text { Squamous cell } \\
\text { carcinoma }\end{array}$ & $368(89.1 \%)$ & $509(86.1 \%)$ & & $320(87.9 \%)$ & $313(86.0 \%)$ & \\
\hline Adenocarcinoma & $37(9.0 \%)$ & $71(12.0 \%)$ & & $36(9.9 \%)$ & $41(11.3 \%)$ & \\
\hline $\begin{array}{l}\text { Adenosquamous } \\
\text { carcinoma }\end{array}$ & $8(1.9 \%)$ & $11(1.9 \%)$ & & $8(2.2 \%)$ & $10(2.7 \%)$ & \\
\hline Tumour size & & & ¿. 001 & & & 0.495 \\
\hline$\leq 4 \mathrm{~cm}$ & $342(82.8 \%)$ & $508(86.0 \%)$ & & $318(87.4 \%)$ & $328(90.1 \%)$ & \\
\hline$\bigotimes 4 \mathrm{~cm}$ & $42(10.2 \%)$ & $76(12.9 \%)$ & & $39(10.7 \%)$ & $30(8.2 \%)$ & \\
\hline Unknows & $29(7.0 \%)$ & $7(1.2 \%)$ & & $7(1.9 \%)$ & $6(1.6 \%)$ & \\
\hline LVSI & & & $\begin{array}{l}<.001 \\
0\end{array}$ & & & 0.672 \\
\hline Negative & $363(87.9 \%)$ & $426(72.1 \%)$ & & $314(86.3 \%)$ & $310(85.2 \%)$ & \\
\hline Positive & $50(12.1 \%)$ & $165(27.9 \%)$ & & $50(13.7 \%)$ & $54(14.8 \%)$ & \\
\hline $\begin{array}{l}\text { Stromal invasion } \\
\text { depth }\end{array}$ & & & 0.021 & & & 0.868 \\
\hline
\end{tabular}




\begin{tabular}{|c|c|c|c|c|c|c|}
\hline \multirow[b]{2}{*}{ Characteristic } & \multicolumn{2}{|c|}{ before matched } & \multirow[t]{2}{*}{$P$} & \multicolumn{2}{|c|}{ after matched } & \multirow[t]{2}{*}{$P$} \\
\hline & $\begin{array}{l}\text { First } 50 \\
\text { patients with } \\
\operatorname{LRH}(n=413)\end{array}$ & $\begin{array}{l}\text { Last } 50 \\
\text { patients with } \\
\operatorname{LRH}(\mathrm{n}=591)\end{array}$ & & $\begin{array}{l}\text { First } 50 \\
\text { patients } \\
\text { with LRH(n } \\
=364)\end{array}$ & $\begin{array}{l}\text { Last } 50 \\
\text { patientes } \\
\text { with LRH(n } \\
=364)\end{array}$ & \\
\hline$\leq 1 / 2$ & $202(48.9 \%)$ & $237(40.1 \%)$ & & $175(48.1 \%)$ & $181(49.7 \%)$ & \\
\hline$\otimes 1 / 2$ & $176(42.6 \%)$ & $298(50.4 \%)$ & & $158(43.4 \%)$ & $155(42.6 \%)$ & \\
\hline Unknows & $35(8.5 \%)$ & $56(9.5 \%)$ & & $31(8.5 \%)$ & $28(7.7 \%)$ & \\
\hline Parametrium & & & 0.573 & & & 0.362 \\
\hline Negative & 406(98.3\%) & $578(97.8 \%)$ & & $357(98.1 \%)$ & $360(98.9 \%)$ & \\
\hline Positive & $7(1.7 \%)$ & $13(2.2 \%)$ & & $7(1.9 \%)$ & $4(1.1 \%)$ & \\
\hline Surgical margin & & & 0.135 & & & 0.704 \\
\hline Negative & $404(97.8 \%)$ & $585(99.0 \%)$ & & $361(99.2 \%)$ & $360(98.9 \%)$ & \\
\hline Positive & $9(2.2 \%)$ & $6(1.0 \%)$ & & $3(0.8 \%)$ & $4(1.1 \%)$ & \\
\hline $\begin{array}{l}\text { pelvic lymph } \\
\text { nodes }\end{array}$ & & & 0.836 & & & 0.128 \\
\hline Negative & $346(83.8 \%)$ & $498(84.3 \%)$ & & $308(84.6 \%)$ & $322(88.5 \%)$ & \\
\hline Positive & $67(16.2 \%)$ & $93(15.7 \%)$ & & $56(15.4 \%)$ & $42(11.5 \%)$ & \\
\hline $\begin{array}{l}\text { postoperative } \\
\text { treatment }\end{array}$ & & & 0.185 & & & 0.103 \\
\hline $\begin{array}{l}\text { Standard } \\
\text { treatment }\end{array}$ & $187(45.3 \%)$ & $305(51.6 \%)$ & & $170(46.7 \%)$ & $187(51.4 \%)$ & \\
\hline $\begin{array}{l}\text { Insufficient } \\
\text { treatment }\end{array}$ & $52(12.6 \%)$ & $75(12.7 \%)$ & & $42(11.5 \%)$ & $27(7.4 \%)$ & \\
\hline Over treatment & 163(39.5\%) & $200(33.8 \%)$ & & $150(41.2 \%)$ & $144(39.6 \%)$ & \\
\hline Uncertain & $11(2.7 \%)$ & $11(1.9 \%)$ & & $2(0.5 \%)$ & $6(1.6 \%)$ & \\
\hline
\end{tabular}

There was no difference in 5-year OS and DFS between the first 50 patients with LRH group $(n=413)$ and the last 50 patients with LRH group $(n=591)$ (OS: $94.6 \%$ vs $96.6 \%, P=0.388$; DFS: $87.6 \%$ vs $90.5 \%, P=$ 0.226) (see in Fig. 2). Cox multivariate analysis (see in Table 3) showed that surgical experience was not an independent risk factor for poor OS in patients with early stage cervical cancer $(p=0.830)$ or an independent risk factor for poor DFS $(p=0.300)$. 
Table 3

Association of Surgical Experience of LRH and Survival outcome of first 50 patients with LRH group and last 50 patients with LRH group $(n=1004)$

\begin{tabular}{|c|c|c|c|c|c|c|}
\hline \multirow[t]{2}{*}{ Parameters } & \multicolumn{3}{|c|}{$\begin{array}{l}\text { Multivariate analysis for 5-year } \\
\text { OS }\end{array}$} & \multicolumn{3}{|c|}{$\begin{array}{l}\text { Multivariate analysis for 5-year } \\
\text { DFS }\end{array}$} \\
\hline & HR & $95.0 \% \mathrm{Cl}$ & $\mathbf{P}$ & HR & $95 \% \mathrm{Cl}$ & $\mathbf{p}$ \\
\hline Age(years) & - & - & 0.703 & - & - & 0.736 \\
\hline Surgeons' experience & - & - & 0.830 & - & - & 0.300 \\
\hline FIGO stage & - & - & 0.447 & - & - & 0.765 \\
\hline Histologic type & - & - & 0.241 & & - & 0.049 \\
\hline Squamous cell carcinoma & & & & 1(Ref) & - & - \\
\hline Adenocarcinoma & - & - & - & 1.471 & $0.775-2.793$ & 0.238 \\
\hline $\begin{array}{l}\text { Adenosquamous } \\
\text { carcinoma }\end{array}$ & - & - & - & 3.209 & $1.164-8.845$ & 0.024 \\
\hline Tumour size & - & - & 0.419 & - & - & 0.944 \\
\hline LVSI & - & - & 0.042 & - & - & 0.718 \\
\hline Negative & 1(Ref) & - & - & - & - & - \\
\hline Positive & 2.252 & $1.030-4.927$ & 0.042 & - & - & - \\
\hline Stromal invasion depth & - & - & 0.019 & - & - & 0.011 \\
\hline$\leq 1 / 2$ & 1(Ref) & - & - & 1(Ref) & - & - \\
\hline$>1 / 2$ & 3.954 & $1.465-10.669$ & 0.007 & 2.208 & $1.296-3.761$ & 0.004 \\
\hline unknows & 4.253 & $1.136-15.924$ & 0.032 & 2.227 & $1.011-4.909$ & 0.047 \\
\hline Parametrium & - & - & 0.159 & - & - & 0.792 \\
\hline Surgical margin & - & - & 0.413 & - & - & 0.655 \\
\hline pelvic lymph nodes & - & - & 0.159 & 2.685 & $1.661-4.340$ & 0.000 \\
\hline postoperative treatment & - & - & 0.903 & - & - & 0.689 \\
\hline \multicolumn{7}{|c|}{ Multicollinearity test and cox proportional hazard regression models were used for analysis. } \\
\hline \multicolumn{7}{|c|}{ Proportional hazard assumption was tested and showed no interaction with time. } \\
\hline Bold indicates significant $P$ & alue. & & & & & \\
\hline
\end{tabular}

After propensity score matching, a total of 728 patients (364 in first 50 patients with LRH group and 364 in last 50 patients with LRH group) met the criteria for inclusion. The baseline data of patients after 
matching were consistent (Table 1). OS was $93.8 \%$ in group first 50 patients with LRH group and $96.9 \%$ in group last 50 patients with LRH group (see in Fig. 2). There was no significant difference in OS between the two groups $(p=0.764)$. Cox multivariate analysis (see in Table 4) showed that LRH surgical experience was not associated with $O S$ in patients with early stage cervical cancer $(p=0.410)$. DFS was $87.2 \%$ in first 50 patients with LRH group and $91.8 \%$ in last 50 patients with LRH group. There was no significant difference in DFS between the two groups $(p=0.705)$. Cox multivariate analysis showed that the experience of LRH surgery was not correlated with DFS in patients with early stage cervical cancer ( $p$ $=0.522$ ). 
Table 4

After matched, association of Surgical Experience of LRH and Survival outcome of first 50 patients with LRH group and last 50 patients with LRH group $(n=728)$

\begin{tabular}{|c|c|c|c|c|c|c|}
\hline \multirow[t]{2}{*}{ Parameters } & \multicolumn{3}{|c|}{$\begin{array}{l}\text { Multivariate analysis for 5-year } \\
\text { OS }\end{array}$} & \multicolumn{3}{|c|}{$\begin{array}{l}\text { Multivariate analysis for 5-year } \\
\text { DFS }\end{array}$} \\
\hline & HR & $95.0 \% \mathrm{Cl}$ & $\mathbf{P}$ & HR & $95 \% \mathrm{Cl}$ & $\mathbf{p}$ \\
\hline Age(years) & - & - & 0.264 & - & - & 0.728 \\
\hline Surgeons' experience & - & - & 0.767 & - & - & 0.522 \\
\hline FIGO stage & - & - & 0.546 & - & - & 0.614 \\
\hline Histologic type & - & - & 0.434 & - & - & 0.034 \\
\hline Squamous cell carcinoma & - & - & - & 1(Ref) & - & - \\
\hline Adenocarcinoma & - & - & - & 1.584 & $0.772-3.247$ & 0.209 \\
\hline $\begin{array}{l}\text { Adenosquamous } \\
\text { carcinoma }\end{array}$ & - & - & - & 3.543 & $1.266-9.919$ & 0.016 \\
\hline Tumour size & - & - & 0.018 & - & - & 0.461 \\
\hline$\leq 4 \mathrm{~cm}$ & 1(Ref) & & & - & - & - \\
\hline$\bigotimes 4 \mathrm{~cm}$ & 1.160 & $0.332-4.047$ & 0.816 & - & - & - \\
\hline Unknows & 6.141 & $1.744-21.621$ & 0.005 & - & - & - \\
\hline LVSI & - & - & 0.073 & - & - & 0.610 \\
\hline Stromal invasion depth & - & - & 0.015 & - & - & 0.008 \\
\hline$\leq 1 / 2$ & 1(Ref) & - & - & 1 (Ref) & - & - \\
\hline$>1 / 2$ & 4.334 & $1.422-13.213$ & 0.010 & 2.421 & $1.310-4.474$ & 0.005 \\
\hline unknows & 6.325 & $1.576-25.380$ & 0.009 & 3.133 & $1.268-7.740$ & 0.013 \\
\hline Parametrium & - & - & 0.508 & - & - & 0.465 \\
\hline Surgical margin & - & - & 0.563 & - & - & 0.363 \\
\hline pelvic lymph nodes & - & - & 0.334 & 3.030 & $1.717-5.347$ & 0.000 \\
\hline postoperative treatment & - & - & 0.731 & - & - & 0.715 \\
\hline \multicolumn{7}{|c|}{ Multicollinearity test and cox proportional hazard regression models were used for analysis. } \\
\hline \multicolumn{7}{|c|}{ Proportional hazard assumption was tested and showed no interaction with time. } \\
\hline Bold indicates significant & & & & & & \\
\hline
\end{tabular}


The same results were obtained from the subgroup analysis of standard postoperative adjuvant therapy(Fig. 3,Table 5-6). The baselines of FIGO staging, histological type, tumour size, LVSI, cervical stromal invation depth and surgical margin were not consistent between the two groups (Table 2). The OS was $95.6 \%$ in first 50 patients with LRH group $(n=187)$ and $95.8 \%$ in last 50 patients with LRH group $(n=305)$ before standard treatment (see in Fig. 3). There was no significant difference in OS between the two groups $(p=0.189)$. Cox multivariate analysis (see in Table 5 ) showed that LRH surgical experience was not associated with OS in patients with early stage cervical cancer $(p=0.189)$. DFS was $90.2 \%$ in first 50 patients with LRH group and $92.2 \%$ in last 50 patients with LRH group (see in Fig. 3). There was no significant difference in DFS between the two groups $(p=0.280)$. Cox multivariate analysis showed that LRH operation experience was not related to DFS in patients with early stage cervical cancer $(p=$ 0.516). The similar result were obtained after matching (see in Table 2 and Table 6). 
Table 2

Clinical and pathological parameters of standart post-operative therapy subgroup of first and last 50 patients with LRH

\begin{tabular}{|c|c|c|c|c|c|c|}
\hline & before match & & $P$ & after matche & & $P$ \\
\hline Characteristic & $\begin{array}{l}\text { First } 50 \\
\text { patients with } \\
\operatorname{LRH}(n=187)\end{array}$ & $\begin{array}{l}\text { Last } 50 \\
\text { patients with } \\
\operatorname{LRH}(\mathrm{n}=305)\end{array}$ & & $\begin{array}{l}\text { First } 50 \\
\text { patients } \\
\text { with LRH(n } \\
=166)\end{array}$ & $\begin{array}{l}\text { Last } 50 \\
\text { patients } \\
\text { with LRH(n } \\
=166)\end{array}$ & \\
\hline Age(years) & $46.9 \pm 8.499$ & $48.0 \pm 9.901$ & 0.221 & $46.9 \pm 8.327$ & $47.1 \pm 9.753$ & 0.799 \\
\hline FIGO stage & & & 0.002 & & & 0.999 \\
\hline IA & $11(5.9 \%)$ & $8(2.6 \%)$ & & $6(3.6 \%)$ & $7(4.2 \%)$ & \\
\hline IB1 & $127(67.9 \%)$ & $205(67.2 \%)$ & & $122(73.5 \%)$ & $120(72.3 \%)$ & \\
\hline IB2 & $20(10.7 \%)$ & $29(9.5 \%)$ & & $18(10.8 \%)$ & $18(10.8 \%)$ & \\
\hline$\| \mathrm{A} 1$ & $18(9.6 \%)$ & $40(13.1 \%)$ & & $16(9.6 \%)$ & $16(9.6 \%)$ & \\
\hline IIA2 & $4(2.1 \%)$ & $22(7.2 \%)$ & & $3(1.8 \%)$ & $4(2.4 \%)$ & \\
\hline $\mathrm{IB} / \mathrm{II} \mathrm{A}$ & $7(3.7 \%)$ & $1(0.3 \%)$ & & $1(0.6 \%)$ & $1(0.6 \%)$ & \\
\hline Histologic type & & & 0.040 & & & 0.845 \\
\hline $\begin{array}{l}\text { Squamous cell } \\
\text { carcinoma }\end{array}$ & $175(93.6 \%)$ & $263(86.2 \%)$ & & $156(94.0 \%)$ & $155(93.4 \%)$ & \\
\hline Adenocarcinoma & $10(5.3 \%)$ & $36(11.8 \%)$ & & $9(5.4 \%)$ & $9(5.4 \%)$ & \\
\hline $\begin{array}{l}\text { Adenosquamous } \\
\text { carcinoma }\end{array}$ & $2(1.1 \%)$ & $6(2.0 \%)$ & & $1(0.6 \%)$ & $2(1.2 \%)$ & \\
\hline Tumour size & & & 0.009 & & & 0.987 \\
\hline$\leq 4 \mathrm{~cm}$ & $156(83.4 \%)$ & $253(83.0 \%)$ & & $144(86.7 \%)$ & $143(86.1 \%)$ & \\
\hline$\nabla 4 \mathrm{~cm}$ & $24(12.8 \%)$ & $51(16.7 \%)$ & & $21(12.7 \%)$ & $22(13.3 \%)$ & \\
\hline Unknows & $7(3.7 \%)$ & $1(0.3 \%)$ & & $1(0.6 \%)$ & $1(0.6 \%)$ & \\
\hline LVSI & & & $<.001$ & & & 0.875 \\
\hline Negative & $161(86.1 \%)$ & $210(68.9 \%)$ & & $142(85.5 \%)$ & $143(86.1 \%)$ & \\
\hline Positive & $26(13.9 \%)$ & $95(31.1 \%)$ & & $24(14.5 \%)$ & $23(13.9 \%)$ & \\
\hline $\begin{array}{l}\text { Stromal invasion } \\
\text { depth }\end{array}$ & & & 0.002 & & & 0.992 \\
\hline
\end{tabular}




\begin{tabular}{|c|c|c|c|c|c|c|}
\hline & before match & & $P$ & after matche & & $P$ \\
\hline Characteristic & $\begin{array}{l}\text { First } 50 \\
\text { patients with } \\
\operatorname{LRH}(n=187)\end{array}$ & $\begin{array}{l}\text { Last } 50 \\
\text { patients with } \\
\operatorname{LRH}(\mathrm{n}=305)\end{array}$ & & $\begin{array}{l}\text { First } 50 \\
\text { patients } \\
\text { with LRH(n } \\
=166)\end{array}$ & $\begin{array}{l}\text { Last } 50 \\
\text { patients } \\
\text { with LRH(n } \\
=166)\end{array}$ & \\
\hline$\leq 1 / 2$ & $110(58.8 \%)$ & $144(47.2 \%)$ & & $99(59.6 \%)$ & $100(60.2 \%)$ & \\
\hline$\otimes 1 / 2$ & $56(29.9 \%)$ & $139(45.6 \%)$ & & $50(30.1 \%)$ & $49(29.5 \%)$ & \\
\hline Unknows & $21(11.2 \%)$ & $22(7.2 \%)$ & & $17(10.2 \%)$ & $17(10.2 \%)$ & \\
\hline Parametrium & & & 0.736 & & & 0.474 \\
\hline Negative & 183(97.9\%) & $297(97.4 \%)$ & & 163(98.2\%) & $161(97.0 \%)$ & \\
\hline Positive & $4(2.1 \%)$ & $8(2.6 \%)$ & & $3(1.8 \%)$ & $5(3.0 \%)$ & \\
\hline Surgical margin & & & 0.030 & & & 1.000 \\
\hline Negative & $181(96.8 \%)$ & $303(99.3 \%)$ & & 164(98.8\%) & $164(98.8 \%)$ & \\
\hline Positive & $6(3.2 \%)$ & $2(0.7 \%)$ & & $2(1.2 \%)$ & $2(1.2 \%)$ & \\
\hline $\begin{array}{l}\text { pelvic lymph } \\
\text { nodes }\end{array}$ & & & 0.834 & & & 0.104 \\
\hline Negative & $150(80.2 \%)$ & $247(81.0 \%)$ & & 133(80.1\%) & $144(86.7 \%)$ & \\
\hline Positive & $37(19.8 \%)$ & $58(19.0 \%)$ & & $33(19.9 \%)$ & $22(13.3 \%)$ & \\
\hline
\end{tabular}


Table 5

Association of Surgical Experience of LRH and Survival outcome of standart post-operative therapy subgroup of first and last 50 patients with LRH $(n=492)$

\begin{tabular}{|c|c|c|c|c|c|c|}
\hline \multirow[t]{2}{*}{ Parameters } & \multicolumn{3}{|c|}{$\begin{array}{l}\text { Multivariate analysis for 5-year } \\
\text { OS }\end{array}$} & \multicolumn{3}{|c|}{$\begin{array}{l}\text { Multivariate analysis for 5-year } \\
\text { DFS }\end{array}$} \\
\hline & HR & $95.0 \% \mathrm{Cl}$ & $\mathbf{P}$ & HR & $95 \% \mathrm{Cl}$ & p \\
\hline Age(years) & - & - & 0.945 & - & - & 0.142 \\
\hline Surgeons' experience & - & - & 0.162 & - & - & 0.294 \\
\hline FIGO stage & - & - & 0.263 & - & - & 0.259 \\
\hline Histologic type & - & - & 0.096 & - & - & 0.008 \\
\hline Squamous cell carcinoma & - & - & - & 1 (Ref) & - & - \\
\hline Adenocarcinoma & - & - & - & 2.575 & $0.956-6.934$ & 0.061 \\
\hline $\begin{array}{l}\text { Adenosquamous } \\
\text { carcinoma }\end{array}$ & - & - & - & 8.067 & $1.818-35.788$ & 0.006 \\
\hline Tumour size & - & - & 0.142 & - & - & 0.176 \\
\hline LVSI & - & - & 0.801 & - & - & 0.278 \\
\hline Stromal invasion depth & - & - & 0.304 & - & - & 0.079 \\
\hline Parametrium & - & - & 0.500 & - & - & 0.311 \\
\hline Surgical margin & - & - & 0.601 & - & - & 0.458 \\
\hline pelvic lymph nodes & - & - & 0.015 & - & - & 0.011 \\
\hline Negative & 1(Ref) & - & - & 1 (Ref) & - & - \\
\hline Positive & 4.651 & $1.344-16.089$ & 0.015 & 2.765 & $1.262-6.061$ & 0.011 \\
\hline \multicolumn{7}{|c|}{ Multicollinearity test and cox proportional hazard regression models were used for analysis. } \\
\hline \multicolumn{7}{|c|}{ Proportional hazard assumption was tested and showed no interaction with time. } \\
\hline Bold indicates significant $\mathrm{F}$ & alue. & & & & & \\
\hline
\end{tabular}


Table 6

After matched, association of Surgical Experience of LRH and Survival outcome of standart postoperative therapy subgroup of first and last 50 patients with LRH $(n=332)$

\begin{tabular}{|c|c|c|c|c|c|c|}
\hline \multirow[t]{2}{*}{ Parameters } & \multicolumn{3}{|c|}{ Multivariate analysis for 5-year OS } & \multicolumn{3}{|c|}{ Multivariate analysis for 5-year DFS } \\
\hline & HR & $95.0 \% \mathrm{Cl}$ & $\mathbf{P}$ & HR & $95 \% \mathrm{Cl}$ & $p$ \\
\hline Age(years) & - & - & 0.191 & - & - & 0.876 \\
\hline Surgeons' experience & - & - & 0.725 & - & - & 0.604 \\
\hline FIGO stage & - & - & 0.902 & - & - & 0.580 \\
\hline Histologic type & - & - & 0.055 & - & - & 0.400 \\
\hline Tumour size & - & - & 0.917 & - & - & 0.739 \\
\hline LVSI & - & - & 0.157 & - & - & 0.057 \\
\hline Stromal invasion depth & - & - & 0.743 & - & - & 0.137 \\
\hline Parametrium & - & - & 0.616 & - & - & 0.516 \\
\hline Surgical margin & - & - & 0.746 & - & - & 0.634 \\
\hline pelvic lymph nodes & - & - & 0.022 & - & - & 0.084 \\
\hline Negative & 1(Ref) & - & - & - & - & - \\
\hline Positive & 8.153 & $1.562-48.805$ & 0.022 & - & - & - \\
\hline postoperative treatment & - & - & 0.191 & - & - & 0.876 \\
\hline \multicolumn{7}{|c|}{ Multicollinearity test and cox proportional hazard regression models were used for analysis. } \\
\hline \multicolumn{7}{|c|}{ Proportional hazard assumption was tested and showed no interaction with time. } \\
\hline Bolc & alue. & & & & & \\
\hline
\end{tabular}

\section{Discussion}

Our study found that long-term oncological outcomes in patients with early stage cervical cancer did not improve significantly with increased surgical experience for high LRH volume surgeons.

The inclusion and exclusion criteria are relatively loose in the general analysis, and the results could reflect the influence of surgeons' LRH experience on survival outcomes of early stage cervical cancer patients. In matched cohort studies, the patients' baseline data were more uniform than those in the RWD, and mixed bias could be effectively controlled. However, the external validity of the results was poor, which meant that the ability to generalize the results to other groups of patients with cervical cancer was limited. ${ }^{21,22}$ In this study, general analysis and matched cohort studies were consistent and mutually 
validated, which improved the reliability of the results. ${ }^{23}$ This further confirmed that the surgical experience of LRH surgeons was not related to the oncological outcomes of the patients.

At present, there are no original articles to study the reasons for the worse laparoscopic oncologic outcome of women with cervical cancer from the perspective of the experience of surgeons, but after the publication of LACC study, some articles ${ }^{9-12}$ discussed whether the experience of surgeons could be one of the reasons for the worse laparoscopic oncologic outcome of women with cervical cancer. However, previous studies analyzed fewer institutions, surgeons and fewer patients than this study. For example, Chong et al. ${ }^{13}$ compared the earliest 50 patients with LRH of a surgeon in a single center with the next 50 patients with LRH in patients with locally advanced cervical cancer. With an increase in surgical experience, the operation time, hospitalization days, time to recover normal residual urine and blood transfusion decreased, the number of lymph nodes obtained increased, and the intraoperative and postoperative complications decreased significantly. For each group, the five-year OS rates were $96 \%$ and $92 \%$, and the five-year DFS rates were $92 \%$ and $90 \%$. The differences were not statistically significant, and the study did not provide a reason for the lack of significant differences in long-term oncological outcomes. However, our finding differ from another study of surgeon experience on prostate cancer. Vickers et al. ${ }^{14}$ conducted a retrospective cohort study of 4702 patients with prostate cancer treated by laparoscopy. A total of 29 surgeons from 7 hospitals participated in the study. It was found that the 5year recurrence rate was $16.3 \%, 11.0 \%$ and $7.1 \%(p=0.038)$ for patients treated by surgeons with 10,250 and 750 laparoscopic surgeries, respectively, and that the increase in surgical experience was associated with the oncological outcomes of patients with prostate cancer.

Matsuo et al. ${ }^{15}$ conducted a nationwide multicenter retrospective study on the RH surgical volume of early stage cervical cancer. A total of 5964 patients with stage IB1-IIB cervical cancer were enrolled from 2004 to 2008. It was found that RH surgical volume may be a prognostic factor for early stage cervical cancer. High surgical volume hospitals may be associated with a reduced risk for local recurrence and an improved survival rate. In this study, there were fewer than $32 \mathrm{RH}$ operations in low volume hospitals, 32 to $104 \mathrm{RH}$ operations in medium volume hospitals and more than $105 \mathrm{RH}$ operations in high volume hospitals over a five-year period. However, the number of surgeries in hospitals could not fully equal to the experience of the surgeons. High-volume hospitals also have doctors with less experience in surgery, and low-volume hospitals also have surgeons with a high surgical volume. The lack of information on surgical approaches in this study means that researchers cannot adjust for the confounding factors of surgical approaches to oncological outcomes. Recent studies such as the study by Ramirez et al. ${ }^{2}$ suggest that LRH is associated with poor oncological outcomes in patients with early stage cervical cancer. This study addresses the lack of research on surgeons' experience and surgical approaches highlighted in Matsuo et al.. ${ }^{15}$

Our study found that the oncological outcomes of patients with early stage cervical cancer was not affected by the LRH experience of surgeons. According to literatures on the learning curve of laparoscopic surgery for cervical cancer, surgeons need 20-50 surgeries to master laparoscopic surgery. 
13,16-20 Therefore, number 50 was selected as the cutting point of surgical experience in this study to compare the oncologic outcomes of the first 50 surgeries and the last 50 surgeries of surgeons with more than 100 surgeries. Our database collected consecutive surgical cases (both open and laparoscopic) of more than 600 surgeons. We screened 7,670 patients who underwent laparoscopic QM-B and C2 hysterectomy. Among them, there are 19 surgeons having more than $100 \mathrm{LRH}$ surgeries, so 1,900 patients with their first 50 and last 50 surgeries were included in this study. On the basis of these 1,900 patients, we strictly included and excluded the following criteria. Finally, 1004 patients were selected for oncologic outcome analysis, including 413 patients in the first 50 LRH group and 591 patients in the last 50 LRH group.

Patients enrolled in this study received postoperative adjuvant therapy according to NCCN and FIGO guidelines. FIGO guideline in $2018^{8}$ mentioned that postoperative adjuvant therapy was added to patients, with any two of three factors intermediate- risk prognostic factors or with any one of high-risk prognostic factors. The high-risk prognostic factors included positive surgical margins or lymph node metastases or parametrial spread, and the intermediate- risk prognostic factors included tumor size more than $4 \mathrm{~cm}$, lymphovascular invasion, deep stromal invasion. This study is a retrospective study. The earliest cases started from 2004, and Sedlis standard was officially recommended by NCCN guideline in $2015^{24}$. Therefore, the standards adopted in this study are not completely consistent with Sedlis standard.

The similar survival outcome were observed in both general and subgroup analysis, before or after matching. It might be explained by the following reason. The first cervical cancer surgery case of this study has been recorded since January 2004 when LRH had been introduced in mainland China not so long. Only few experienced surgeons with a high volume of ARH started LRH. Most of the nineteen surgeons in our study were those surgeons who were pioneers on $\mathrm{LRH}$, their enriched surgical experience of $A R H$ helped them to conquer the difficulty on transferring ARH to $L R H$, so they mastered LRH technique more easily. It might explain why the 5-year OS and DFS results in the first 50 patients with LRH group were not poorer than the last 50 patients with LRH group in this study.

We acknowledge several limitations in this study. First, this study only analyzed the effect of LRH surgical experience on the efficacy of $\mathrm{LRH}$, without considering the effect of ARH experience on the efficacy of $\mathrm{LRH}$. Second, this study is a retrospective study, although multivariate analysis and propensity score matching could effectively control for known confounding factors, the impact of confounding factors on result could not be eliminated completely. Third, this study only analyzed the overall survival rate and disease-free survival rate but did not analyze the recurrence patterns, which requires further study. Fourth, there may be differences in the writing standards of cases and reports in different hospitals, leading to a lack of some clinical data. Fifth, in China, gynecologists perform laparoscopic radical hysterectomy with Wertheim-Meigs operation. Patients with stage IB1 to IIA2 cervical cancer underwent QM-C radical hysterectomy and pelvic lymph node dissection. Patients with stage IA1 with positive LVSI to IA2 cervical cancer underwent QM-B radical hysterectomy. However, this study is a retrospective study. It is a pity that 
this database lacks specific surgical procedures. Whether we used a uterine manipulation, or made a vaginal stuff is not available.

\section{Conclusion}

The oncological outcomes of the first 50 surgeries performed by high-volume LRH surgeons were similar to those of the last 50 surgeries in patients with early stage cervical cancer. The long-term oncological outcomes of LRH in patients with stage IA1 with positive LVSI to stage IIA2 cervical cancer did not improve with an increase in surgeons' experience.

\section{Declarations}

\section{Ethics approval and consent to participate}

This retrospective study was approved by the Ethics Committee of the Nanfang Hospital of Southern Medical University (approval number NFEC-2017-135 and clinical trial number CHiCTR1800017778; International Clinical Trials Registry Platform Search Port, http://apps.who.int/trialsearch/); registration date: August 14, 2018. Written consent to participate in the study was provided by all patients.

\section{Consent for publication}

Not Applicable.

\section{Availability of data and material}

The datasets used and/or analysed during the current study are available from the corresponding author upon reasonable request.

\section{Competing interests}

The authors declare that they have no competing interests to disclose.

\section{Funding}

The National Science and Technology Support Program of China (2014BAI05B03)

The Natural Science Foundation of Guangdong Province(2015A030311024)

The Science and Technology Plan of Guangzhou (158100075)

The above funding sources provided financial assistance that had an important role in data collection.

\section{Authors' contributions}


1. Pengfei Li did the literature search, data collection, data analysis and interpretation, drafted and revised the manuscript

2. Shan Kang conceived and designed the study, interpreted the data, developed and revised the manuscript.

3. Jianxin Guo conceived and designed the study, interpreted the data, developed and revised the manuscript.

4. Shiqi Liang did the literature search, data analysis and interpretation and figures, drafted and revised the manuscript.

5. Ying Yang conceived, designed the study, interpreted the data. conceived, designed the study, interpreted the data.

6. Shaoguang Wang conceived, designed the study, interpreted the data.

7. Xiaonong Bin did the data analysis and interpretation.

8. Jinghe Lang conceived, designed and supervised the study.

9. Ping Liu conceived, designed and supervised the study.

10. Chunlin Chen conceived, designed and supervised the study.

All authors read and approved the final manuscript.

\section{Acknowledgements}

This study received funding of the National Science and Technology Support Program of China (2014BAI05B03), the National Natural Science Fund of Guangdong (2015A030311024), the Science and Technology Plan of Guangzhou (158100075). We thank Min Hao (The second hospital of ShanXi medical university), Bin Ling (China-Japan Friendship Hospital), Lixin Sun and Hongwei Zhao (Shanxi Cancer Hospital), Jihong Liu and Lizhi Liang (Sun Yat-sen University Cancer Center), Lihong Lin and Yu Guo (Anyang Tumor Hospital ), Li Wang (The Affiliated Tumor Hospital of Zhengzhou University), Weidong Zhao (Anhui Provincial Cancer Hospital), Yan Ni (The Yuncheng central hospital of Shanxi province), Wentong Liang and Donglin Li (Guizhou Provincial People's Hospital), Xuemei Zhan and Mingwei Li (Jiangmen Central Hospital), Weifeng Zhang (Ningbo Women \& Children's Hospital), Peiyan Du (The Affiliated Cancer Hospital and Institute of Guangzhou Medical University), Ziyu Fang (Liuzhou workers' hospital), Rui Yang (Shenzhen hospital of Peking University), Long Chen (Qingdao Municipal Hospital), Encheng Dai and Ruilei Liu (Linyi People's Hospital), Yuanli He and Mubiao Liu (Zhujiang Hospital, Southern Medical University), Jilong Yao and Zhihua Liu (Shenzhen Maternity \& Child Health Hospital), Xueqin Wang (The Fifth Affiliated Hospital of Southern Medical University), Anwei Lu (Maternal and Child Health Hospital of Guiyang Province), Shuangling Jin (Peace Hospital affiliated to Changzhi Medical College), Ben Ma (Guangzhou First People's Hospital), Zhonghai Wang (Shenzhen Nanshan People's Hospital), Lin Zhu (The Second Hospital of Shandong University), Hongxin Pan (The Third Affiliated Hospital of Shenzhen University), Qianyong Zhu (No.153. Center Hospital of Liberation Army /Hospital No.988 of the Chinese People's Liberation Army Joint Support Force), Dingyuan Zeng and 
Zhong Lin (Maternal and Child Health Care Hospital of Liuzhou), Xiaohong Wang (Laiwu People's Hospital/Jinan City People's Hospital) and Bin Zhu (The Affiliated Yiwu Women and Children Hospital of Hangzhou Medical College) for their contribution in data collection.

\section{Authors' information (optional)}

\section{Corresponding author}

\section{$1 \quad$ Chunlin Chen, PhD}

Department of Obstetrics and Gynecology, Nanfang Hospital, Southern Medical University, No. 1838 Guangzhou Avenue, Guangzhou 510515, China. E-mail address: ccl1@smu.edu.cn. Tel: +86 02062787562. ORCID囚0000-0002-1708-3047

\section{Ping Liu MD/PhD}

Department of Obstetrics and Gynecology, Nanfang Hospital, Southern Medical University, No. 1838, Guangzhou Avenue, Guangzhou 510515, China. E-mail address: Ipivy@126.com. Tel: +86 02087705641.

\section{Contributed equally to this work}

$1 \quad$ Pengfei Li[MD/PhD

Department of Obstetrics and Gynecology, Nanfang Hospital, Southern Medical University, Guangzhou 510515, China, Email: 16241@smu.edu.cn

\section{Shan Kang $\square \mathrm{MD} / \mathrm{PhD}$}

Department of Gynecology , Fourth Hospital『Hebei Medical University,Shijiazhuang 050019, China, Email: ksjq62cn@sina.com

\section{Jianxin GuolMD/PhD}

Department of Obstetrics and Gynecology $₫$ Daping hospital, Army Medical University, Chongqing, 400042,China, Email: 470040@qq.com

\section{$4 \quad$ Shiqi Liang $\square \mathrm{MD}$}

Department of Obstetrics and Gynecology, Nanfang Hospital, Southern Medical University, Guangzhou 510515, China, Email: shclsq@163.com

\section{Other authors}

\section{Ying Yang $\mathrm{MD} / \mathrm{PhD}$}


Department of Obstetrics and Gynecology $₫$ Xinqiao Hospital $\triangle$ Army Medical University, Chongqing 400037, China, Email: heyalh@126.com

\section{Shaoguang WangDMD/PhD}

Department of Gynecology, The Affiliated Yantai Yuhuangding Hospital of Qingdao University, Yantai 264000, China, Email: shaoguangw@sina.com

Xiaonong Bin, BA

Department of Epidemiology, College of Public Health, Guangzhou Medical University, Email: gzbxn@163.com

\section{Jinghe Lang, MD/PhD}

1 Department of Obstetrics and Gynecology, Nanfang Hospital, Southern Medical University, Guangzhou 510515 , China

2 Department of Obstetrics and Gynecology, Peking Union Medical College Hospital, Chinese Academy of Medical Science and Peking Union Medical College, Beijing 100730, China.

Email: langjh@hotmail.com

\section{References}

1. NCCN Clinical Practice Guidelines in Oncology (NCCN Guidelines®). Cervical Cancer. Version 2.2019 - October 12, 2018. 286 https://www.nccn.org/professionals/physician_gls/pdf/cervical.pdf).

2. Ramirez PT, Frumovitz M, Pareja R, et al. Minimally Invasive versus Abdominal Radical Hysterectomy for Cervical Cancer. N Engl J Med. 2018;379(20):1895-904. doi:10.1056/NEJMoa1806395.

3. Melamed A, Margul DJ, Chen L, et al. Survival after Minimally Invasive Radical Hysterectomy for Early-Stage Cervical Cancer. N Engl J Med. 2018;379(20):1905-14. doi:10.1056/NEJMoa1804923.

4. Koh WJ, Abu-Rustum NR, Bean S, et al. Cervical Cancer, Version 3.2019, NCCN Clinical Practice Guidelines in Oncology. J Natl Compr Canc Netw. 2019;17(1):64-84. doi:10.6004/jnccn.2019.0001.

5. Zhang W, Chen C, Liu P, et al. Staging early cervical cancer in China: data from a multicenter collaborative. Int J Gynecol Cancer. 2019. doi:10.1136/ijgc-2019-000263.

6. Zhang W, Chen C, Liu P, Li W, et al. Impact of pelvic MRI in routine clinical practice on staging of IB1IIA2 cervical cancer. Cancer Manag Res. 2019;11:3603-9. doi:10.2147/CMAR.S197496.

7. Querleu D, Morrow CP. Classification of radical hysterectomy. Lancet Oncol. 2008;9(3):297-303. doi: 10.1016/S1470-2045(08)70074-3.

8. Bhatla N, Aoki D, Sharma DN, Sankaranarayanan R. Cancer of the cervix uteri. International Journal of Gynecology Obstetrics. 2018;143:22-36. doi:10.1002/ijgo.12611. 
9. Kanao H, Aoki Y, Takeshima N. Unexpected result of minimally invasive surgery for cervical cancer. Journal of Gynecologic Oncology. 2018;29(4) 'doi': 10.3802/jgo.2018.29.e73.

10. Park J, Nam J. How should gynecologic oncologists react to the unexpected results of LACC trial? Journal of Gynecologic Oncology. 2018;29(4) 'doi': 10.3802/jgo.2018.29.e74.

11. Kimmig R, Ind T. Minimally invasive surgery for cervical cancer: consequences for treatment after LACC Study. Journal of Gynecologic Oncology. 2018;29(4) 'doi': 10.3802/jgo.2018.29.e75.

12. Vergote I, Magrina JF, Zanagnolo V, Magtibay PM, et al. The LACC Trial and Minimally Invasive Surgery in Cervical Cancer. Journal of Minimally Invasive Gynecology. 2019. 10.1016/j.jmig.2019.09.767. 'doi':.

13. Chong GO, Park NY, Hong DG, Cho YL, Park IS, Lee YS. Learning Curve of Laparoscopic Radical Hysterectomy With Pelvic and/or Para-Aortic Lymphadenectomy in the Early and Locally Advanced Cervical Cancer. Int J Gynecol Cancer. 2009;19(8):1459-64. doi:10.1111/IGC.0b013e3181b76640.

14. Vickers AJ, Savage CJ, Hruza M, et al. The surgical learning curve for laparoscopic radical prostatectomy: a retrospective cohort study. Lancet Oncol. 2009;10(5):475-80. doi:10.1016/S14702045(09)70079-8.

15. Matsuo K, Shimada M, Yamaguchi S, Matoda M, et al. Association of Radical Hysterectomy Surgical Volume and Survival for Early-Stage Cervical Cancer. Obstet Gynecol. 2019;133(6):1086-98. doi:10.1097/AOG.0000000000003280.

16. Hwang JH, Yoo HJ, Joo J, Kim S, et al. Learning curve analysis of laparoscopic radical hysterectomy and lymph node dissection in early cervical cancer. European Journal of Obstetrics Gynecology Reproductive Biology. 2012;163(2):219-23. 10.1016/j.ejogrb.2012.05.005. 'doi':.

17. Chong GO, Lee YH, Hong DG, Cho YL, Park IS, Lee YS. Robot Versus Laparoscopic Nerve-Sparing Radical Hysterectomy for Cervical Cancer. Int J Gynecol Cancer. 2013;23(6):1146-50. 10.1097/IGC.0b013e31829a5db0. 'doi':.

18. Yim GW, Kim SW, Nam EJ, Kim S, Kim YT. Learning curve analysis of robot-assisted radical hysterectomy for cervical cancer: initial experience at a single institution. Journal of Gynecologic Oncology. 2013;24(4):303. 10.3802/jgo.2013.24.4.303. 'doi':.

19. Sandadi S, Gadzinski JA, Lee S, Chi DS, et al. Fellowship learning curve associated with completing a robotic assisted total laparoscopic hysterectomy. Gynecol Oncol. 2014;132(1):102-6. 10.1016/j.ygyno.2013.11.017. 'doi':.

20. Oyama K, Kanno K, Kojima R, Shirane A, et al. Short-term outcomes of robotic-assisted versus conventional laparoscopic radical hysterectomy for early-stage cervical cancer: A single-center study. Journal of Obstetrics Gynaecology Research. 2019;45(2):405-11. 10.1111/jog.13858. 'doi':.

21. Fleurence RL, Blake K, Shuren J. The Future of Registries in the Era of Real-world Evidence for Medical Devices. JAMA cardiology. 2019;4(3):197-8. doi:10.1001/jamacardio.2018.4933.

22. Yuan H, Ali MS, Brouwer ES, et al. Real-World Evidence: What It Is and What It Can Tell Us According to the International Society for Pharmacoepidemiology (ISPE) Comparative Effectiveness Research (CER) Special Interest Group (SIG). Clin Pharmacol Ther. 2018;104(2):239-41. doi:10.1002/cpt.1086. 
23. Sherman RE, Anderson SA, Dal Pan GJ, Gray GW, et al. Real-World Evidence - What Is It and What Can It Tell Us? N Engl J Med. 2016;375(23):2293-7. doi:10.1056/NEJMsb1609216.

24. Cervical Cancer, Version 2.2015. Journal of the National Comprehensive Cancer Network,13(4), 395404. doi:10.6004/jnccn.2015.0055.

\section{Figures}

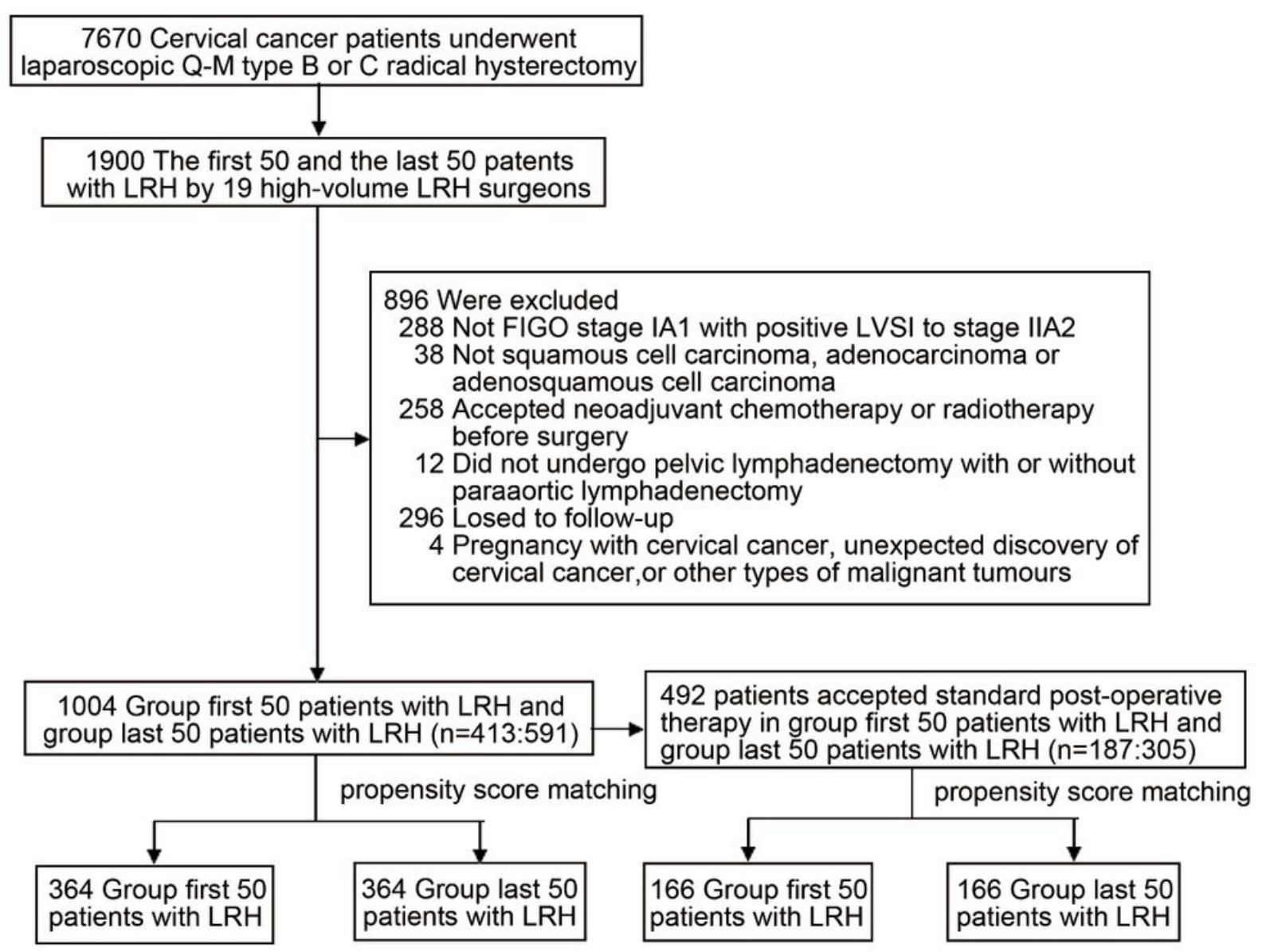

\section{Figure 1}

Study population. 


\section{General analysis}

A

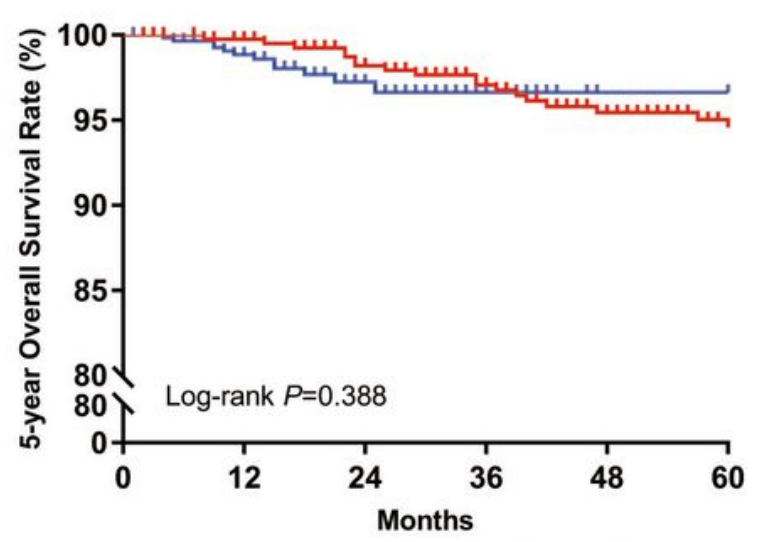

5-year Overall Survival Events Rates

\begin{tabular}{lccc}
\hline $\begin{array}{l}\text { Group fitst 50 } \\
\text { patients with LRH }\end{array}$ & 413 & 18 & $94.6 \%$ \\
$\begin{array}{l}\text { Group last } 50 \\
\text { patients with LRH }\end{array}$ & 591 & 12 & $96.6 \%$
\end{tabular}

B

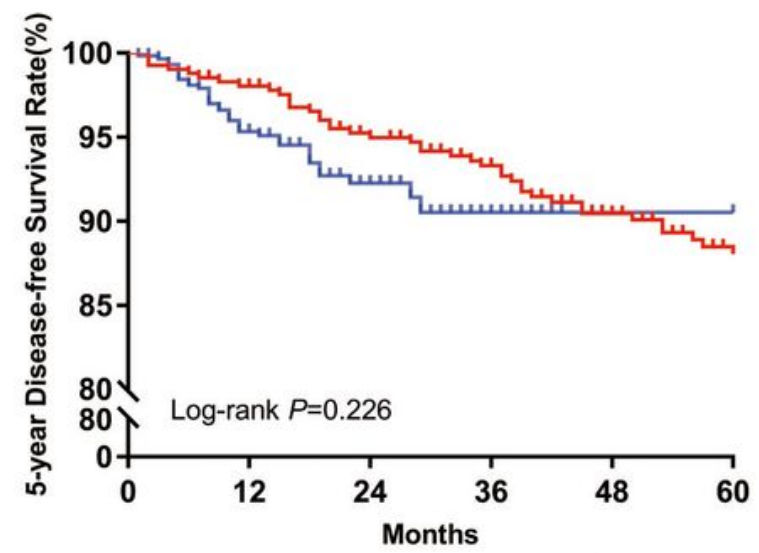

5-year Disease-free Survival Events Rates

\begin{tabular}{lccc}
\hline $\begin{array}{l}\text { Group fitst 50 } \\
\text { patients with LRH }\end{array}$ & 413 & 43 & $87.6 \%$ \\
$\begin{array}{l}\text { Group last 50 } \\
\text { patients with LRH }\end{array}$ & 591 & 36 & $90.5 \%$
\end{tabular}

\section{General analysis after matched}

C

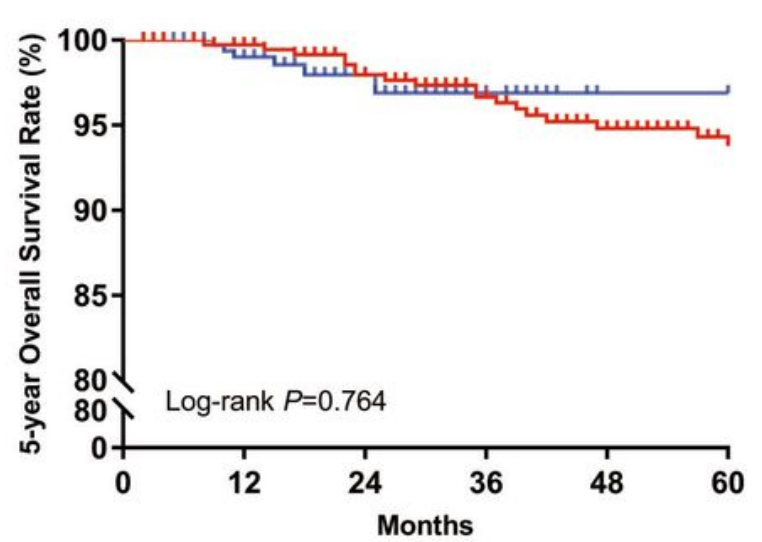

5-year Overall Survival

\begin{tabular}{lccc} 
& $\mathrm{N}$ & Events & Rates \\
\hline $\begin{array}{l}\text { Group fitst 50 } \\
\text { patients with LRH }\end{array}$ & 364 & 18 & $93.8 \%$ \\
$\begin{array}{l}\text { Group last 50 } \\
\text { patients with LRH }\end{array}$ & 364 & 6 & $96.9 \%$
\end{tabular}

D

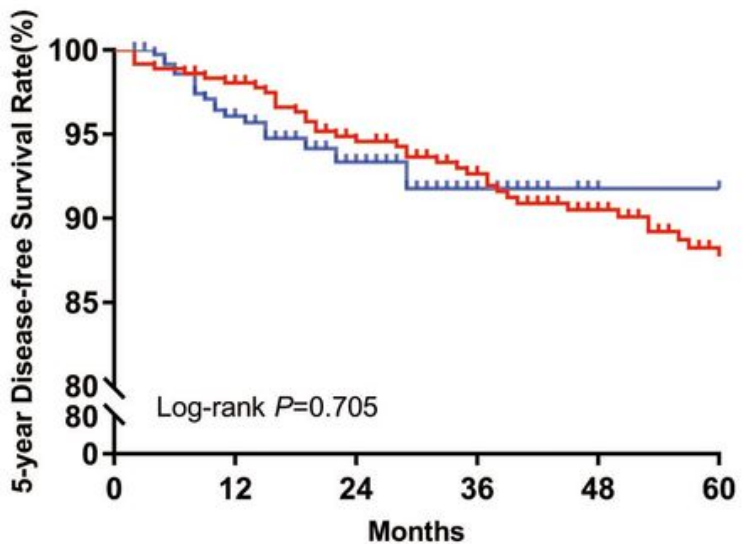

5-year Disease-free Survival $\mathrm{N}$ Events Rates

\begin{tabular}{llll}
\hline Group fitst 50 & 364 & 39 & $87.2 \%$
\end{tabular}

Group last $50 \quad 364 \quad 19 \quad 91.8 \%$

\section{Figure 2}

Survival analysis of the first 50 patients with LRH group and the last 50 patients with LRH group $(A, B)$ and after propensity score matching(C,D). The 5-year OS(A) and 5-year DFS(B) were not associated with surgeons' experience while comparing the first 50 cases to last 50 cases(OS: $94.6 \%$ vs $96.6 \%, p=0.388$; DFS: $87.6 \%$ vs $90.5 \%, p=0.226)$. After PSM, similar result were observed in the 5 -year OS(C) and 5-year DFS(D) $(93.8 \%$ vs $96.9 \%, P=0.764 ; 87.2 \%$ vs $91.8 \%, P=0.705)$. 


\section{Subgroup of postoperative standard treatment}

A

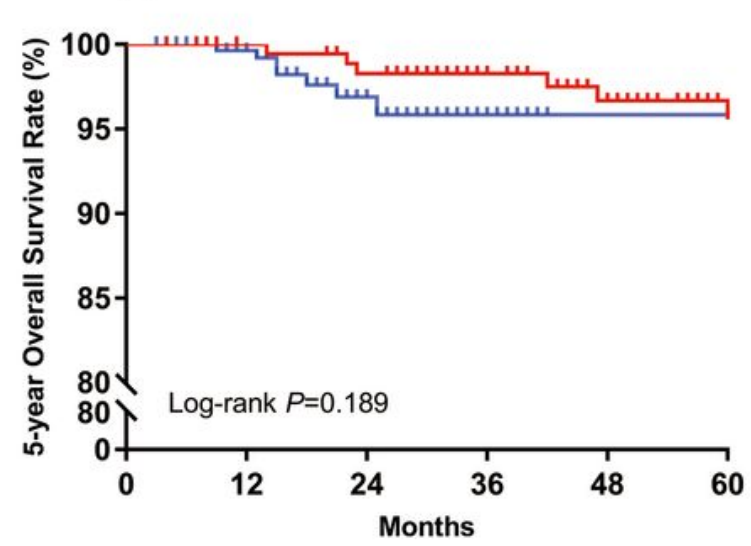

5-year Overall Survival

\begin{tabular}{lccc} 
& $\mathrm{N}$ & Events & Rates \\
\hline $\begin{array}{l}\text { Group fitst 50 } \\
\text { patients with LRH }\end{array}$ & 187 & 6 & $95.6 \%$ \\
$\begin{array}{l}\text { Group last 50 } \\
\text { patients with LRH }\end{array}$ & 305 & 7 & $95.8 \%$
\end{tabular}

B

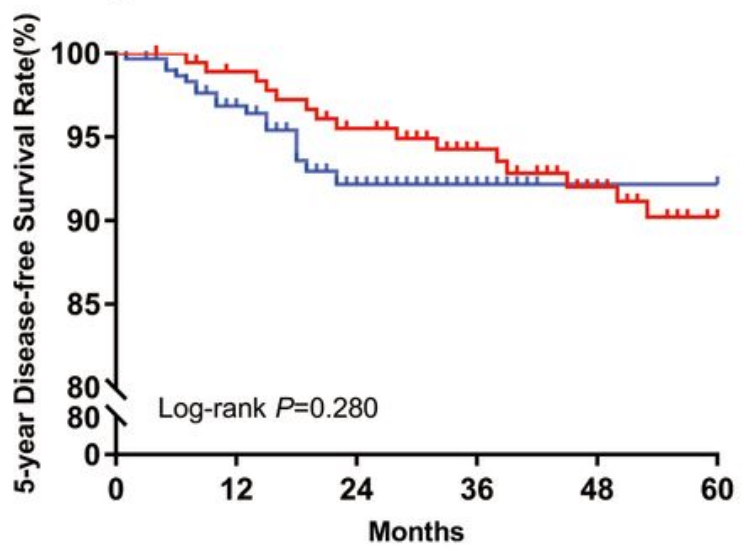

5-year Disease-free Survival $\mathrm{N}$ Events Rates \begin{tabular}{llll}
\hline Group fitst 50 & 187 & 15 & $90.2 \%$ \\
patients with LRH
\end{tabular} $305 \quad 17$

$92.2 \%$

\section{Subgroup of postoperative standard treatment after matched}

C

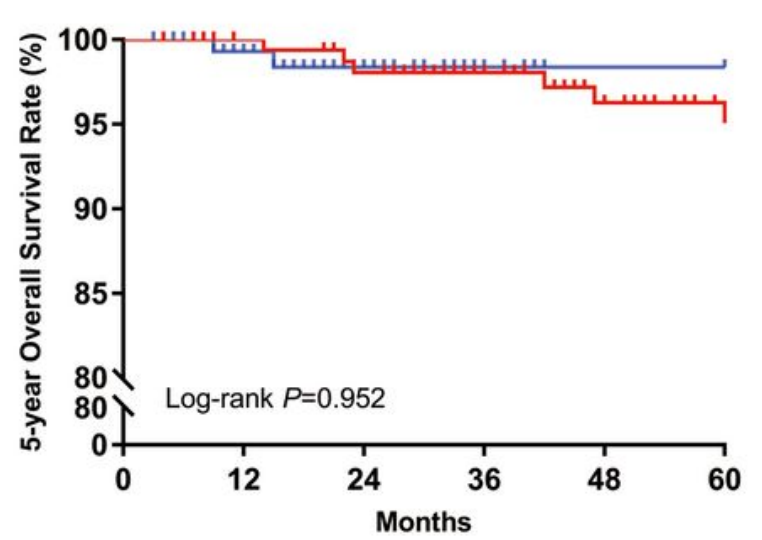

5-year Overall Survival

\begin{tabular}{lccc} 
& $\mathrm{N}$ & Events & Rates \\
\hline $\begin{array}{l}\text { Group fitst 50 } \\
\text { patients with LRH }\end{array}$ & 166 & 6 & $95.1 \%$ \\
$\begin{array}{l}\text { Group last 50 } \\
\text { patients with LRH }\end{array}$ & 166 & 2 & $98.4 \%$
\end{tabular}

$\mathrm{D}$

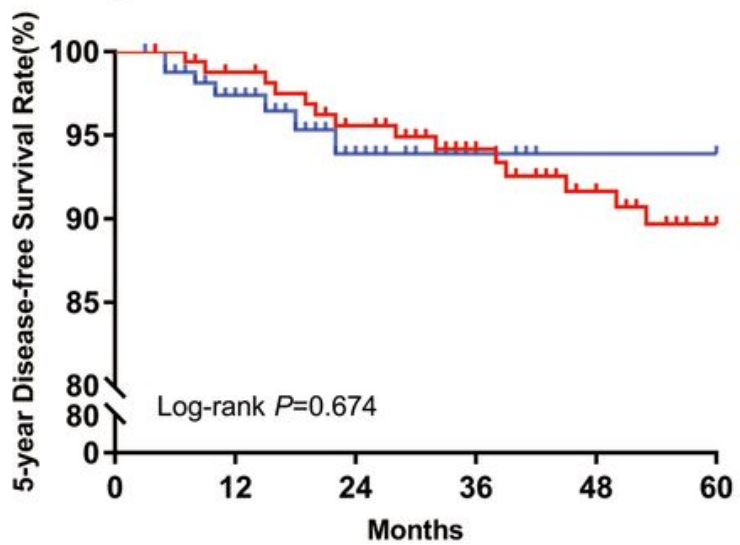

5-year Disease-free Survival $\mathrm{N}$ Events Rates

\begin{tabular}{lccc} 
& $\mathrm{N}$ & Events & Rates \\
\hline $\begin{array}{l}\text { Group fitst 50 } \\
\text { patients with LRH }\end{array}$ & 166 & 14 & $89.7 \%$ \\
$\begin{array}{l}\text { Group last 50 } \\
\text { patients with LRH }\end{array}$ & 166 & 7 & $93.9 \%$
\end{tabular}

\section{Figure 3}

Survival analysis of the first 50 patients with LRH group and the last 50 patients with LRH group in the subgroup of standard postoperative therapy $(A, B)$ and after propensity score matching $(C, D)$. For patients received standard postoperative therapy after LRH, the 5-year OS(A) and 5-year DFS(B) were not associated with surgeons' experience while comparing the first 50 cases to last 50 cases (OS: $95.6 \%$ vs 
$95.8 \%, P=0.189 ;$ DFS: $90.2 \%$ vs $92.2 \%, P=0.280)$. After $P S M$, similar result were observed in the 5 -year OS(C) and 5-year DFS(D) (OS: $95.1 \%$ vs $98.4 \%, P=0.952$; DFS: $89.7 \%$ vs $93.9 \%, P=0.674$ ). 